\title{
Adult Neurogenesis in Humans
}

\author{
Olaf Bergmann, Kirsty L. Spalding, and Jonas Frisén \\ Department of Cell and Molecular Biology, Karolinska Institute, SE-171 77 Stockholm, Sweden \\ Correspondence: jonas.frisen@ki.se
}

\begin{abstract}
Adult neurogenesis appears very well conserved among mammals. It was, however, not until recently that quantitative data on the extent of this process became available in humans, largely because of methodological challenges to study this process in man. There is substantial hippocampal neurogenesis in adult humans, but humans appear unique among mammals in that there is no detectable olfactory bulb neurogenesis but continuous addition of new neurons in the striatum.
\end{abstract}

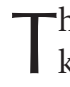
here has been an enormous expansion in the knowledge regarding adult neurogenesis in experimental animals over the last two decades. A strong motivation in this research field has been that similar processes are likely to operate in humans, and that alterations in adult neurogenesis could underlie neurological or psychiatric diseases. Moreover, many have hoped that the potential of resident neural stem cells could be harnessed to promote the generation of new neurons for cell replacement in neurological diseases. A seminal study by Eriksson, Gage and colleagues (Eriksson et al. 1998), in which they were able to show the presence of 5-bromo2-deoxyuridine (BrdU) in hippocampal neurons of cancer patients who had received the label for diagnostic purposes, established the presence of adult-born neurons in the human hippocampus. This study was exceptionally important in that it provided strong evidence for the presence of adult neurogenesis in humans. However, it did not enable any quantitative estimates, and a lingering question has been whether adult neurogenesis decreased with pri- mate evolution, and whether the extent of this process in humans is sufficient to have any functional impact (Rakic 1985; Kempermann 2012).

\section{ANALYSIS OF ADULT NEUROGENESIS IN HUMANS}

Several studies have shed light on adult neurogenesis in humans by quantifying the number of cells displaying neuroblast markers in the human postmortem brain. In humans, doublecortin (DCX) and polysialylated neuronal cell adhesion molecule (PSA-NCAM)-expressing putative neuroblasts are found in both the dentate gyrus (DG) of the hippocampus (Knoth et al. 2010) in the lateral ventricle wall (Sanai et al. 2011; Wang et al. 2011), the neurogenic niche for olfactory bulb neurons in other mammals. The density of neuroblasts in both these two regions is highest in the perinatal period, and drops dramatically during the first few postnatal months, to then decline more slowly throughout life (Göritz and Frisén 2012). A limitation with the analysis of neuroblast markers

Editors: Fred H. Gage, Gerd Kempermann, and Hongjun Song

Additional Perspectives on Neurogenesis available at www.cshperspectives.org

Copyright (C) 2015 Cold Spring Harbor Laboratory Press; all rights reserved; doi: 10.1101/cshperspect.a018994

Cite this article as Cold Spring Harb Perspect Biol 2015;7:a018994 
O. Bergmann et al.

is that it is not possible to know whether they differentiate to become mature neurons and integrate long term. A large number of studies have been performed with markers associated with neurogenesis in several human pathologies (Curtis et al. 2012), but the uncertainties with these types of markers makes it difficult to draw a firm conclusion regarding neurogenesis.

The process of adult neurogenesis is most often studied in experimental animals by prospectively labeling newborn cells. This can be done, for example, by administering labeled nucleotides, which integrate stably in DNA when it is duplicated during mitosis, or genetic labeling with retroviruses or transgenic strategies. A common factor for all strategies used in experimental animals is that they entail first introducing a stable mark in cells, specific for cell proliferation (in the case of labeled nucleotides or retroviruses), or the origin from a candidate stem or progenitor cells (in transgenic strategies), and later assessing whether such a mark is present in mature neurons, which then indicates neurogenesis. Prospective labeling strategies are difficult to apply in humans, as any mark that is stably integrated in genomic DNA may introduce mutations or be toxic in other ways. Moreover, one needs to wait until the person dies so that the brain can be analyzed. With these substantial hurdles, it is not surprising that there have not been more studies managing to assess adult neurogenesis in humans by labeled nucleotide incorporation (Eriksson et al. 1998).

The challenges associated with prospectively labeling adult-born neurons in humans prompted us to develop a strategy to retrospectively determine the age of cells, and in that way assess the turnover dynamics within a cell population (Fig. 1). Aboveground nuclear bomb

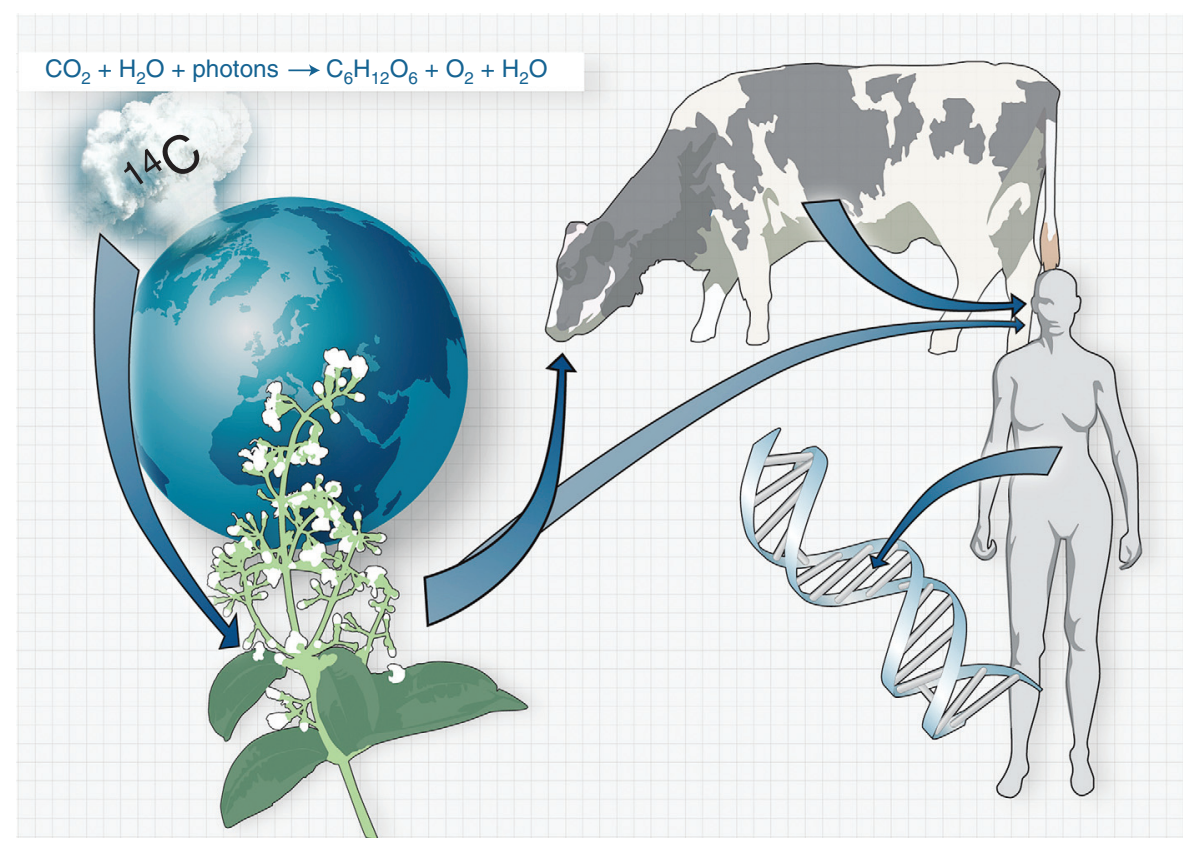

Figure 1. Retrospective birth dating of cells. Schematic depiction of the strategy to retrospectively birth date cells. Nuclear bomb tests during the Cold War resulted in a large addition of ${ }^{14} \mathrm{C}$ to the atmosphere. ${ }^{14} \mathrm{C}$ in the atmosphere reacts with oxygen to form ${ }^{14} \mathrm{CO}_{2}$, which is taken up by plants in photosynthesis. Eating plants or animals living off plants results in the atmospheric ${ }^{14} \mathrm{C}$ concentrations at any given time being mirrored in the human body. When a cell divides and duplicates its genome, it will integrate ${ }^{14} \mathrm{C}$ in DNA with a concentration corresponding to that in the atmosphere at any given time. Measuring the ${ }^{14} \mathrm{C}$ concentration in genomic DNA allows determination of when cells were born. 
tests conducted during the Cold War in the 1950s and 1960s resulted in an almost doubling of atmospheric ${ }^{14} \mathrm{C}$ (De Vries 1958; Nydal and Lovseth 1965). After the Test Ban Treaty in 1963, the atmospheric ${ }^{14} \mathrm{C}$ levels have since declined owing to a redistribution mainly into the oceans (Levin and Kromer 2004; Levin et al. 2010). In the atmosphere, ${ }^{14} \mathrm{C}$ reacts with oxygen to form ${ }^{14} \mathrm{CO}_{2}$, which enters the food chain through plant photosynthesis. Being at the top of the food pyramid, ${ }^{14} \mathrm{C}$ concentration in the human body closely parallels that in the atmosphere at any given time (Libby et al. 1964; Harkness 1972; Spalding et al. 2005b). When cells undergo mitosis and duplicate their DNA, ${ }^{14} \mathrm{C}$ integrates into genomic DNA, and the ${ }^{14} \mathrm{C}$ concentration remains stable after the last cell division. Relating the measured genomic ${ }^{14} \mathrm{C}$ concentration to atmospheric levels establishes the birth date of cells and their turnover dynamics (Spalding et al. 2005a, 2008; Bhardwaj et al. 2006; Bergmann et al. 2009). This strategy is schematically shown in Figure 1.

Retrospective birth dating was first applied for the analysis of cell turnover in the cerebral cortex (Spalding et al. 2005a; Bhardwaj et al. 2006). Nonneuronal cells had ${ }^{14} \mathrm{C}$ concentrations in their genomic DNA corresponding to times after the birth of the individual, indicating the continuous generation of such cells in the human neocortex. In contrast, neurons from all major subdivisions of the human cerebral cortex had ${ }^{14} \mathrm{C}$ concentrations in genomic DNA that corresponded to the time around the birth of the individual, establishing that most neurons must be as old as the person and that there could have been no major postnatal neurogenesis (Bhardwaj et al. 2006). Moreover, analysis of BrdU incorporation in the cerebral cortex in the material procured by Eriksson and Gage (Eriksson et al. 1998) showed BrdU labeled nonneuronal cells but no labeled neurons. The combined analysis of BrdU and ${ }^{14} \mathrm{C}$ incorporation gave a very high sensitivity to detect rare events, concluding that if there is any adult neurogenesis in the human neocortex, it amounts to maximally the exchange of $1 / 1000$ neurons every fifth year (Bhardwaj et al. 2006). Even after stroke, cortical neurons appear as old as the individual, not supporting any detectable neurogenesis in this situation (Huttner et al. 2014).

\section{SUBVENTRICULAR ZONE}

Neural stem cells residing in the walls of the lateral ventricles of the brain give rise to neuroblasts that migrate to the olfactory bulb throughout life in most mammals. Arturo AlverazBuylla and colleagues investigated the cellular architecture of the human subventricular zone in a large study including 110 surgical and postmortem specimens (Sanai et al. 2004). They identified a ribbon of glial fibrillary acidic protein (GFAP)-expressing astrocytes that parallels the ependymal cell layer, which is different from the rodent subventricular zone. The described interaction in rodents of migratory neuroblasts (type A), astrocytic stem cells (type B), transiently amplifying cells (type C), and ependymal cells could not be seen in the human subventricular zone. In contrast to these findings in adults, the human fetal forebrain revealed a high proliferative activity with cells coexpressing the migrating neuroblast marker DCX and PSA-NCAM (Wang et al. 2011). Similarly, a study of the infant forebrain found expression of DCX and the immature glial marker vimentin in the subventricular zone (Sanai et al. 2011). Most neuroblasts migrated tangentially, but some formed chains within the rostral migratory stream, comparable with chains of migratory neuroblasts in the subventricular zone, and rostral migratory stream of the rodent and monkey brain (Sanai et al. 2011; Wang et al. 2011). In human infant forebrains, an additional migratory stream of DCX-positive cells was identified. These DCX/PSA-NCAM coexpressing cells branch off at the proximal limb of the rostral migratory stream, and head to the ventromedial prefrontal cortex. Proliferation and DCX expression in both infant migratory streams sharply decline after birth. Only a few migratory neuroblasts and limited proliferation in the subventricular zone and rostral migratory stream could be observed after 6 to 8 months of age (Sanai et al. 2011). However, the existence and configuration of the adult ros- 
tral migratory stream with migration chains of neuroblasts has been controversial (Curtis et al. 2007; Sanai et al. 2007). Curtis et al. (2007) reported an extension of the lateral ventricle that reaches the olfactory bulb with highly proliferative cells surrounding this hollow tube. Although the localization of the described rostral migratory stream has been confirmed, the existence of an open ventricular structure and chain migration with high numbers of dividing neuroblasts has been questioned (Sanai et al. 2011; Wang et al. 2011). In the study by Curtis et al. (2007), neuroblast proliferation was mainly documented by immunolabeling with the proliferating cell nuclear antigen (PCNA) antibody. Other studies, however, could only find a small number of Ki67- or MCM2-positive neuroblasts in the adult rostral migratory stream (Sanai et al. 2004, 2011; Wang et al. 2011), suggesting that PCNA immunoreactivity might not be specific to dividing cells in the human brain. Moreover, a recent study suggests that DCX is not restricted to neuroblasts, but has been shown to be expressed in postmitotic neurons in the piriform cortex where DCX is important for synaptic plasticity, and necessary to process olfactory information (Klempin et al. 2011). These data emphasize that the interpretation of markers for neurogenesis and cell proliferation should be done cautiously, particularly when species borders are crossed and/or regions outside well-characterized neurogenic regions are analyzed.

\section{OLFACTORY BULB}

In rodents, large numbers of neuroblasts migrate from the subventricular zone to the olfactory bulb every day (Ming and Song 2011) where they differentiate to interneurons and integrate into the neuronal circuitry. About 40\% of the newly born neurons integrate and survive for $<18$ months (Winner et al. 2002). Adult neurogenesis in the olfactory bulb is not restricted to rodents, but has been found in many mammalian species including adult monkeys (Kornack and Rakic 2001). The new neurons participate in functional synaptic circuitry and are implicated in olfactory memory formation, odorant discrimination, and social interactions (Ming and Song 2011).

In humans, olfaction is only rudimentarily developed compared with other mammals, which might be reflected in the relatively reduced size of the olfactory system, including the olfactory epithelium, the olfactory bulb, and related cortical projection areas. However, $3 \mathrm{D}$ reconstruction of fossil skulls have provided evidence for the olfactory system having evolved in Homo sapiens. Modern humans have larger olfactory bulbs, and relatively wider orbitofrontal and temporal cortices than the early Homo (Bastir et al. 2011). Another fundamental difference between species is the number of olfactory receptor genes. The number of different olfactory receptors is much lower in man compared with mice (350 vs. 1100). However, the number of glomeruli in humans is approximately threefold higher than in mice, resulting in a much higher glomeruli-to-olfactory receptor convergence ratio (Maresh et al. 2008). This finding indicates that, although rodents share similarities in odor processing at the molecular and synaptic level, there are significant differences in glomerular organization in humans compared with mice.

It is not possible to infer the extent of olfactory bulb neurogenesis from the number of stem or progenitor cells in the human subventricular zone. The kinetics of subventricular zone stem cells and the future fate of neuroblasts migrating to the olfactory bulb are not possible to determine. We do not know how many of the neuroblasts give rise to new olfactory interneurons, and how many of these new neurons integrate stably into the circuitry and survive long term. Even a small number of migrating neuroblasts could give rise to a substantial portion of adult-born neurons given an efficient neuronal integration, resulting in long-term survival of the new neurons in the olfactory bulb. Moreover, there is evidence that interneurons in the olfactory bulb are not exclusively derived from subventricular zone stem cells, but may also derive from local progenitor cells residing in the olfactory bulb (Pagano et al. 2000).

Analysis of the ${ }^{14} \mathrm{C}$ concentration in olfactory bulb neuronal DNA from adult humans re- 
vealed levels corresponding to the time around birth of the individual, establishing that there is no significant postnatal neuronal turnover in the human olfactory bulb (Bergmann et al. 2012). Mathematical modeling gave an upper limit of $1 \%$ of neurons being replaced in 100 years of life. These findings suggest that adult olfactory bulb neurogenesis, contrary to most mammals, is absent in adult humans. This might not be surprising because humans rely much less on olfaction than animals. In mice, odor stimuli result in higher survival rates of newborn neurons (Rochefort et al. 2002), and a deprivation of olfactory stimuli in young mice leads to apoptosis in the olfactory glomeruli accompanied by smaller bulbs (Cummings et al. 1997). Have we lost the ability to generate new neurons because our olfactory epithelium has regressed making odors less perceptible for us? Difficult odor discrimination and learning have been associated with the activity and integration of adult-born interneurons in mice (Alonso et al. 2012). Would a more frequent exposure to novel odors from early childhood rescue the decline of neuroblasts migrating toward the olfactory bulb, and support long-term survival of newly born neurons into adulthood, or is human olfaction conceptionally differently modulated?

Deprivation of neurogenesis in the human olfactory bulb has been implicated in several neurodegenerative diseases that compromise olfaction and can lead to anosmia (Turetsky et al. 2000; Höglinger et al. 2004; Hansson et al. 2010; Negoias et al. 2010; Winner et al. 2011). However, the limited or absent olfactory bulb neurogenesis makes it unlikely that the anosmia is a consequence of reduced adult olfactory bulb neurogenesis.

\section{STRIATUM}

The presence of neuroblasts in the subventricular zone in adult humans, but very few migrating along the rostral migratory stream or giving rise to neurons in the olfactory bulb, posed the question of what the fate of these neuroblasts may be. There is no apparent apoptosis of neuroblasts within the adult human subventricular zone (Ernst et al. 2014). An analysis of publicly available transcriptome data from different subdivisions of the human brain revealed expression at all ages of the neuroblast marker DCX in the striatum, located adjacent to the subventricular zone, at levels comparable to those in the hippocampus. Western blot revealed DCX protein levels in the adult human striatum comparable to or higher than in the hippocampus, and immunohistochemistry showed DCX and PSA-NCAM coexpressing putative neuroblasts in the striatum (Ernst et al. 2014).

Generation of new striatal interneurons was shown by the detection of iododeoxyuridine (IdU)-positive neurons in postmortem tissue from cancer patients who had received IdU as a radiosensitizer (Ernst et al. 2014). Carbon dating revealed that neuronal turnover was restricted to the subpopulation of DARP23-negative interneurons, and mathematical modeling indicated a turnover rate of $2.7 \%$ per year within this population (Ernst et al. 2014). Some of the DCX-positive putative neuroblasts, as well as some of the IdU-labeled neurons in the adult human striatum coexpressed the striatal interneuron markers calretinin or neuropeptide $\mathrm{Y}$ (NPY). Interestingly, adult-born striatal neurons are selectively depleted in Huntington's disease (Ernst et al. 2014).

The generation of neuroblasts in the subventricular zone, located adjacent to the striatum, make it tempting to speculate that the new neurons in the adult human striatum derive from the subventricular zone. However, other origins are also possible, and the recent finding that local astrocytes give rise to new striatal neurons in mice after stroke raises the possibility that parenchymal astrocytes may mediate striatal neurogenesis in adult humans (Magnusson et al. 2014). Interestingly, neurogenesis by astrocytes in the mouse striatum is under the control of Notch signaling, and neurogenesis in the healthy adult mouse striatum can be induced by blocking this signaling pathway (Magnusson et al. 2014). This points to a potential therapeutic target for promoting striatal neurogenesis.

Low levels of striatal neurogenesis have been reported in mice, rats, rabbits, and monkeys (Bedard et al. 2002a,b; Dayer et al. 2005; 
O. Bergmann et al.

Tonchev et al. 2005; Luzzati et al. 2006; Inta et al. 2008), so this does not appear to be a humanspecific feature. The extent of striatal neurogenesis does, however, appear to have increased with evolution. Although direct comparisons are difficult owing to a paucity of quantitative data from nonhuman mammals. It is currently difficult to speculate about a potential functional role for striatal neurogenesis. The striatum has traditionally been primarily associated with motor functions. Presently, however, it is appreciated for important cognitive functions. The relative size of the striatum has expanded substantially with evolution and is thought to be important for cognitive flexibility in humans, a type of plasticity that potentially could be influenced by adult neurogenesis (Ernst and Frisén 2015).

\section{HIPPOCAMPUS}

Adult hippocampal neurogenesis has been extensively studied in mice, with distinct developmental stages and marker profiles identified (Kempermann et al. 2004). In an extension of this, Kempermann and colleagues mapped features of rodent hippocampal neurogenesis in human hippocampal tissue. They investigated the pattern of DCX-positive neuroblasts in the adult human DG, using a large cohort of individuals $(n=55)$ ranging in age from 1 day to 100 years (Knoth et al. 2010). DCX-positive cells were found in the DG across the entire lifespan, with DCX-positive cells in young individuals showing dendritic features of immature neurons.

DCX expression was also investigated with other markers shown in rodents to associate with hippocampal neurogenesis. Proliferative markers, such as Ki67 and Mem2, showed cell proliferation in the DG up to at least the ages 38 and 65 years, respectively. Proxl and calretinin, a transcription factor related to granule cell development in rodents and a calcium-binding protein expressed by immature granule cells, respectively, were expressed across the entire lifespan. An overlap between DCX and the mature neuronal marker, NeuN, was also found in individuals up to 85 years. Semiquantitative analysis of DCX labeling in the DG across the lifespan, showed a loglinear decline in labeling, indicating an age-related reduction in neurogenesis. The most significant decline in DCXpositive cells was seen within the first years of life, with approximately a fivefold decrease in the DG from 20 to 100 years.

Neuroimaging has been used as a tool to assess the effects of a variety of parameters that impact hippocampal neurogenesis with hippocampal phenotype. Such parameters include enriched environment and learning, physical activity, aging, stress, depression, and antidepressant treatments. Correlations of these parameters to changes in hippocampal volume have been reported, leading investigators to suggest that a decrease/increase in hippocampal volume relates to changes in hippocampal neurogenesis (for a review on hippocampal volume and major depressive disorder [MDD], see McKinnon et al. [2009]; for a comprehensive review of in vivo imaging of adult human hippocampal neurogenesis, the reader is referred to Ho et al. [2013]). Definitive studies, however, that link imaging outcome measures to adult neurogenesis are yet to be established. Several factors may account for the observed differences in hippocampal volume, such as changes in cell soma size, dendritic complexity, and glial cell size and number.

To assess whether a decrease in hippocampal DG volume in antidepressant treated and untreated individuals suffering from MDD is a result of decreased neurogenesis, mature granule neuron number and DG and granule cell layer volume were determined (Boldrini et al. 2013). Boldrini et al. found that untreated MDD patients had fewer mature granule neurons in the anterior hippocampal DG than antidepressant treated or control individuals (a result consistent with imaging studies of McKinnon et al. [2009]), as well as smaller DG and granule cell layer volumes (estimated stereologically using the Cavalieri method). Although tempting to conclude that neurogenesis occurs in humans and is impaired in untreated MDD individuals, direct evidence for neurogenesis per se, or the effect of antidepressants on hippocampal structural plasticity is still missing. 
Other imaging techniques attempting to measure human hippocampal neurogenesis in vivo include cerebral blood volume (CBV) measurements and magnetic resonance spectroscopy (MRS). CBV maps regional blood volume, and given the established relationship between angiogenesis and neurogenesis (Palmer et al. 2000), it was tested to determine whether a regionally selective increase in CBV may provide an imaging correlate of neurogenesis (Pereira et al. 2007). Based on this relationship (and extrapolated from animal data), the investigators reported that 3 months of aerobic exercise induced neurogenesis. MRS detects metabolites through their unique chemical shifts, in which the area under the signal peak represents the metabolite concentration. Manganas et al. (2007) reported a "neurogenesis-specific" peak at $1.28 \mathrm{ppm}$ in the adult human hippocampus. A significant decline in neurogenesis with age was also reported. Controversy exists, however, as to whether this "neurogenesis peak" actually represents neurogenesis or whether it reflects apoptosis (Ramm et al. 2009). As summarized by Kempermann (2012), any MRI/MRS-based method requires validation studies that include an independent method of assessing human neurogenesis. Nevertheless, such studies provide additional indirect information supportive of a role of hippocampal neurogenesis in human health and pathology.

Radiocarbon analysis of DNA from neuronal and nonneuronal hippocampal cells showed that both populations are turning over in adulthood. Mathematical modeling of ${ }^{14} \mathrm{C}$ data allows for a detailed analysis of neuronal and nonneuronal turnover. By fitting models to the data, it is possible to infer how much cell renewal is needed to reproduce the observed ${ }^{14} \mathrm{C}$, and whether the renewal is restricted to a subpopulation (Bergmann et al. 2009). A large proportion $(51 \%)$ of the nonneuronal cells were found to be continuously exchanged, with a median turnover rate of 3.5\% per year. Mathematical models that allowed subpopulations to have different turnover dynamics fitted the data better, in line with the heterogeneous nature of nonneuronal cells (which are mainly comprised of astrocytes, microglia, and oligo- dendrocyte-lineage cells, as well as several smaller populations, such as leukocytes and blood vessel-associated endothelial and perivascular cells). Estimates of individual turnover rates suggest that there is a decline in nonneuronal cell turnover with age $(r=-0.35, p=0.04)$.

Unlike ${ }^{14} \mathrm{C}$ levels in genomic DNA of neurons from cortex, cerebellum, and olfactory bulb, hippocampal neurons had ${ }^{14} \mathrm{C}$ levels that corresponded to times after the individual's birth year (Fig. 2), indicating neuronal turnover (Spalding et al. 2013). Modeling of the data showed that there are two populations of neurons within the hippocampus, one rather homogenous population (constituting 35\% of hippocampal neurons), turning over at a median rate of $1.75 \%$ per year, and the other not turning over (Fig. 2). The exchange rate of hippocampal neurons declines moderately with age, paralleling the decline in the number of neuroblasts (Fig. 2). This corresponds to $\sim 700$ new neurons per day in each hippocampus, or $0.004 \%$ of the DG neurons exchanged per day. Unlike mice, in which $\sim 10 \%$ of dentate granule neurons are subject to exchange in adulthood (Ninkovic et al. 2007; Imayoshi et al. 2008), nearly all dentate granule neurons turn over in the adult human hippocampus (Spalding et al. 2013).

Stereological investigations of neuronal number in the adult human hippocampus have established that neuronal number declines with age, with neuronal number in the DG least affected (West and Gundersen 1990; West 1993; Simic et al. 1997; Harding et al. 1998; Korbo et al. 2004). In line with this, a relative increase in the proportion of neurons in the renewing fraction fits the ${ }^{14} \mathrm{C}$ data well (Spalding et al. 2013). Within the renewing population of cells, young neurons were found to die faster, supporting the notion of a preferential loss of adult-born neurons. Establishing the turnover dynamics of hippocampal neurons, together with data on the change in neuronal numbers with age, allows the derivation of an integrated model of hippocampal cell dynamics (Fig. 3).

It is not possible to assess the potential function of the continuous hippocampal neurogenesis in humans, but it is possible to compare the extent of this process with other species, which 
O. Bergmann et al.
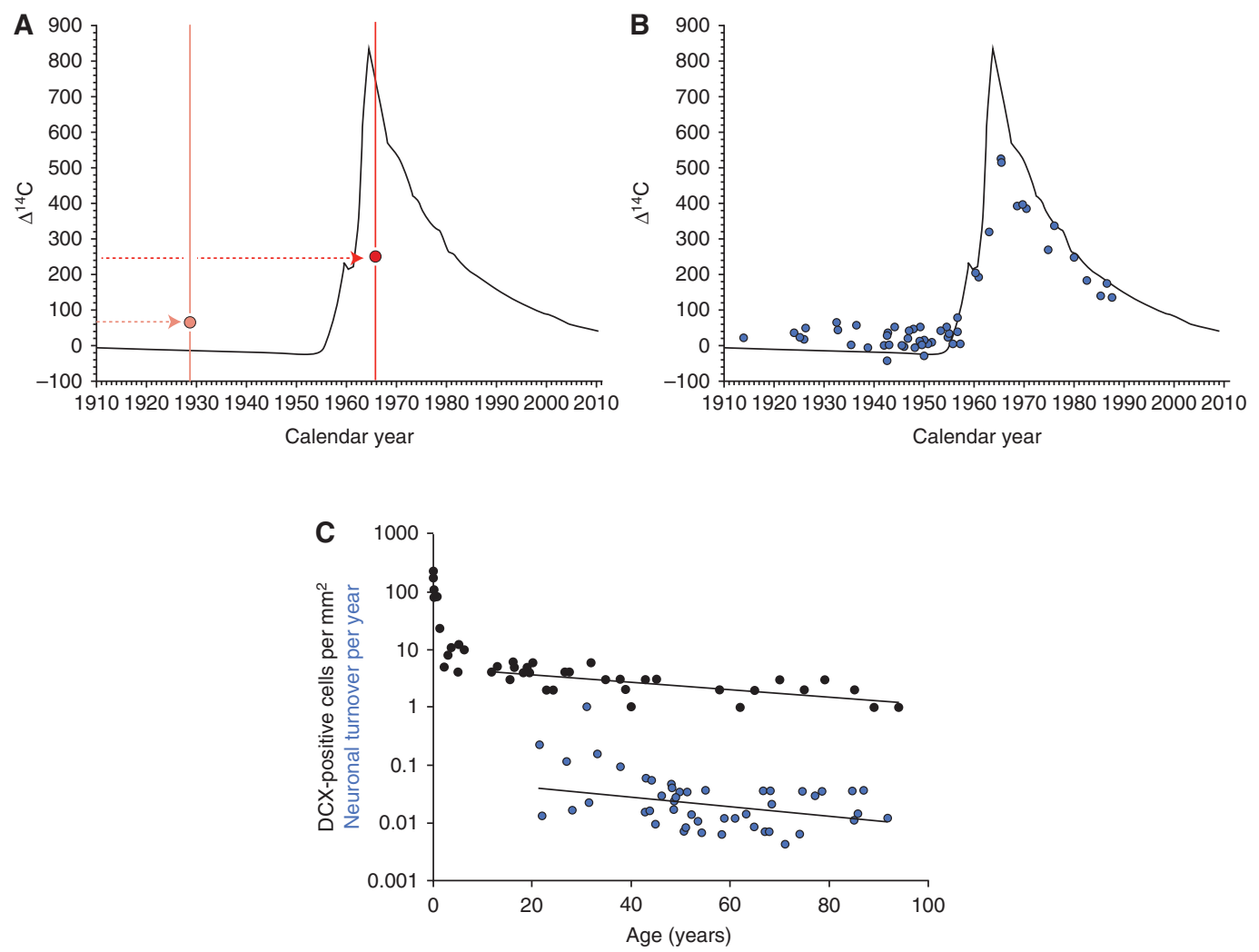

Figure 2. Neuronal turnover in the adult human hippocampus. (A) Schematic illustration of the representation of measured ${ }^{14} \mathrm{C}$ concentrations in genomic DNA based on the year of birth for individuals born before (orange circle) or after (red circle) the nuclear bomb tests. The black line indicates the ${ }^{14} \mathrm{C}$ concentration in the atmosphere at different time points in the last century. (B) Individually measured ${ }^{14} \mathrm{C}$ concentrations in genomic DNA of human hippocampal neurons. ${ }^{14} \mathrm{C}$ concentrations above the atmospheric ${ }^{14} \mathrm{C}$ curve, for subjects born before the onset of nuclear bomb tests, and data points below the curve, for subjects born after the nuclear tests, indicate cell turnover. $(C)$ Individual turnover rates for neurons within the renewing fraction were computed based on individual data fitting (data from Spalding et al. 2013). The number of doublecortin (DCX)-positive cells per $\mathrm{mm}^{2}$ in the dentate gyrus (data from Knoth et al. 2010) shows a similar modest decline during adult ages as the computed neuronal turnover rates. Straight lines depict linear regression curves, with the regression line for DCX cell counts calculated for individuals 10 years and older. Individual turnover rate calculations are sensitive to deviations in measured ${ }^{14} \mathrm{C}$, and values $<0.001$ or $>1.5$ were excluded from the plot; however, the full dataset is given in Spalding et al. (2013).

can provide insights as to whether there is sufficient generation of new cells in humans to play a similar role. Perhaps the best way to compare the extent of neurogenesis between species is to compare the proportion of new to old neurons in the DG (Kempermann 2012). The neuronal exchange rate of $0.004 \%$ DG per day in adult humans, can be compared with $0.03 \%$ to $0.06 \%$ per day in 2-month-old mice and $0.004 \%$ to $0.02 \%$ per day in 5 - to 16 -year-old macaques
(Kempermann et al. 1997; Kornack and Rakic 1999; Jabès et al. 2010). There is an $\sim 10$-fold decline in neurogenesis in mice between 2 and 9 months of age (Ben Abdallah et al. 2010), indicating that the extent of adult hippocampal neurogenesis is comparable in middle-aged mice and humans (Fig. 4). Hippocampal neurogenesis mediates pattern separation in memory formation and cognition in mice (Clelland et al. 2009; Sahay et al. 2011; Nakashiba et al. 
Adult Human Neurogenesis

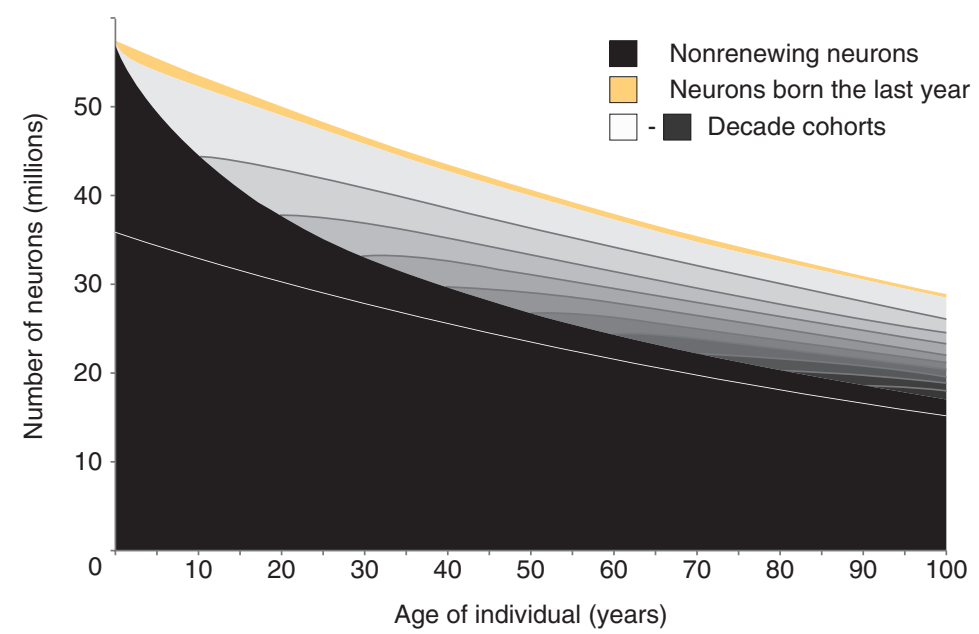

Figure 3. Dynamics of hippocampal neurogenesis in humans. Schematic representation of the change in neuronal number and turnover in the human hippocampus. The dentate gyrus neurons constitute the population above the white line, and the other subdivisions of the hippocampus are shown below the white line. Neurons generated before birth of the individual are depicted in black, and decade cohorts of new neurons are shown in shades of gray. The proportion of cells shown in light gray represent the neurons generated during the last decade, the next shade darker represent the neurons generated the decade before that and so on. Newborn neurons have specific functional properties, and the neurons generated during the last year are depicted in gold. (Figure adapted from Spalding et al. 2013; reproduced, with permission, from the author.)

2012), and it is, thus, possible that adult neurogenesis has a similar function in humans.

\section{CONCLUDING REMARKS}

The substantial neurogenesis in the human hippocampus supports that this process may have important implications for human brain function and disease. There are major differences in adult neurogenesis between humans and rodents, the most commonly studied experimental animals, which makes it important to assess this process in humans in parallel with model organisms. It will be very interesting, albeit

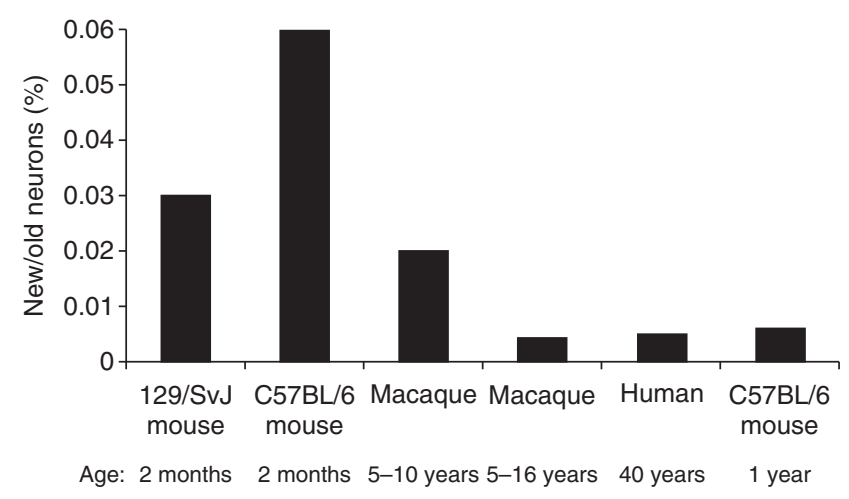

Figure 4. Interspecies comparison of the extent of adult hippocampal neurogenesis. Representation of the proportion of newborn neurons to old neurons in the dentate gyrus, based on published data (Kempermann et al. 1997; Kornack and Rakic 1999; Jabès et al. 2010; Spalding et al. 2013). The extent of neurogenesis in 1-yearold mice was estimated from data from the 2-month-old mouse and the reduction in hippocampal neurogenesis with age in mice (Ben Abdallah et al. 2010). 
O. Bergmann et al.

challenging, to try to decipher the functional role of adult neurogenesis in normal brain function, as well as the role of potentially altered neurogenesis in human disease. Analysis of potential correlations between the extent of neurogenesis and neurological and pathological parameters may motivate the development of strategies to modulate this process in human disease.

\section{ACKNOWLEDGMENTS}

Work in the authors' laboratories is supported by grants from the Swedish Research Council, the Swedish Cancer Society, the Karolinska Institute, Tobias Stiftelsen, AFA Försäkringar, the Strategic Research Programme in Stem Cells and Regenerative Medicine at Karolinska Institutet (StratRegen), Hjärnfonden, Stiftelsen för Strategisk Forskning (SSF), Torsten Söderbergs Stiftelse, the European Research Council (ERC), and Knut och Alice Wallenbergs Stiftelse.

\section{REFERENCES}

Alonso M, Lepousez G, Sebastien W, Bardy C, Gabellec MM, Torquet N, Lledo PM. 2012. Activation of adult-born neurons facilitates learning and memory. Nat Neurosci 15: $897-904$.

Bastir M, Rosas A, Gunz P, Peña-Melian A, Manzi G, Harvati K, Kruszynski R, Stringer C, Hublin J-J. 2011. Evolution of the base of the brain in highly encephalized human species. Nat Commun 2: 588.

Bedard A, Cossette M, Levesque M, Parent A. 2002a. Proliferating cells can differentiate into neurons in the striatum of normal adult monkey. Neurosci Lett 328: 213-216.

Bedard A, Levesque M, Bernier PJ, Parent A. 2002b. The rostral migratory stream in adult squirrel monkeys: Contribution of new neurons to the olfactory tubercle and involvement of the antiapoptotic protein Bcl-2. Eur J Neurosci 16: 1917-1924.

Ben Abdallah NM, Slomianka L, Vyssotski AL, Lipp HP. 2010. Early age-related changes in adult hippocampal neurogenesis in C57 mice. Neurobiol Aging 31: 151-161.

Bergmann O, Bhardwaj RD, Bernard S, Zdunek S, BarnabeHeider F, Walsh S, Zupicich J, Alkass K, Buchholz BA, Druid H, et al. 2009. Evidence for cardiomyocyte renewal in humans. Science 324: 98-102.

Bergmann O, Liebl J, Bernard S, Alkass K, Yeung MSY, Steier P, Kutschera W, Johnson L, Landen M, Druid H, et al 2012. The age of olfactory bulb neurons in humans. Neuron 74: 634-639.

Bhardwaj RD, Curtis MA, Spalding KL, Buchholz BA, Fink D, Bjork-Eriksson T, Nordborg C, Gage FH, Druid H, Eriksson PS, et al. 2006. Neocortical neurogenesis in hu- mans is restricted to development. Proc Natl Acad Sci 103: 12564-12568.

Boldrini M, Santiago AN, Hen R, Dwork AJ, Rosoklija GB, Tamir H, Arango V, John Mann J. 2013. Hippocampal granule neuron number and dentate gyrus volume in antidepressant-treated and untreated major depression. Neuropsychopharmacology 38: 1068-1077.

Clelland CD, Choi M, Romberg C, Clemenson GD Jr, Fragniere A, Tyers P, Jessberger S, Saksida LM, Barker RA, Gage FH, et al. 2009. A functional role for adult hippocampal neurogenesis in spatial pattern separation. Science 325: 210-213.

Cummings DM, Knab BR, Brunjes PC. 1997. Effects of unilateral olfactory deprivation in the developing opossum, Monodelphis domestica. J Neurobiol 33: 429-438.

Curtis MA, Kam M, Nannmark U, Anderson MF, Axell MZ, Wikkelso C, Holtas S, van Roon-Mom WM, Bjork-Eriksson T, Nordborg C, et al. 2007. Human neuroblasts migrate to the olfactory bulb via a lateral ventricular extension. Science 315: 1243-1249.

Curtis MA, Low VF, Faull RL. 2012. Neurogenesis and progenitor cells in the adult human brain: A comparison between hippocampal and subventricular progenitor proliferation. Dev Neurobiol 72: 990-1005.

Dayer AG, Cleaver KM, Abouantoun T, Cameron HA. 2005. New GABAergic interneurons in the adult neocortex and striatum are generated from different precursors. J Cell Biol 168: 415-427.

De Vries H. 1958. Atomic bomb effect: Variation of radiocarbon in plants, shells, and snails in the past 4 years. Science 128: 250-251.

Eriksson PS, Perfilieva E, Björk-Eriksson T, Alborn AM, Nordborg C, Peterson DA, Gage FH. 1998. Neurogenesis in the adult human hippocampus. Nat Med 4: 13131317.

Ernst A, Frisén J. 2015. Adult neurogenesis in humansCommon and unique traits in mammals. PLoS Biol doi: 10.1371/journal.pbio.1002045.

Ernst A, Alkass K, Bernard S, Salehpour M, Perl S, Tisdale J, Possnert G, Druid H, Frisen J. 2014. Neurogenesis in the striatum of the adult human brain. Cell 156: 1072-1083.

Göritz C, Frisén J. 2012. Neural stem cells and neurogenesis in the adult. Cell Stem Cell 10: 657-659.

Hansson AC, Nixon K, Rimondini R, Damadzic R, Sommer WH, Eskay R, Crews FT, Heilig M. 2010. Long-term suppression of forebrain neurogenesis and loss of neuronal progenitor cells following prolonged alcohol dependence in rats. Int J Neuropsychopharmacol 13: 583-593.

Harding AJ, Halliday GM, Kril JJ. 1998. Variation in hippocampal neuron number with age and brain volume. Cereb Cortex 8: 710-718.

Harkness DD. 1972. Further investigations of the transfer of bomb ${ }^{14} \mathrm{C}$ to man. Nature 240: 302-303.

Ho NF, Hooker JM, Sahay A, Holt DJ, Roffman JL. 2013. In vivo imaging of adult human hippocampal neurogenesis: Progress, pitfalls and promise. Mol Psychiatry 18: 404416.

Höglinger GU, Rizk P, Muriel MP, Duyckaerts C, Oertel WH, Caille I, Hirsch EC. 2004. Dopamine depletion impairs precursor cell proliferation in Parkinson disease. Nat Neurosci 7: 726-735. 
Huttner HB, Bergmann O, Salehpour M, Racz A, Tatarishvili J, Lindgren E, Csonka T, Csiba L, Hortobagyi T, Mehes G, et al. 2014. The age and genomic integrity of neurons after cortical stroke in humans. Nat Neurosci 17: 801-803.

Imayoshi I, Sakamoto M, Ohtsuka T, Takao K, Miyakawa T, Yamaguchi M, Mori K, Ikeda T, Itohara S, Kageyama R. 2008. Roles of continuous neurogenesis in the structural and functional integrity of the adult forebrain. $\mathrm{Nat} \mathrm{Neu}$ rosci 11: 1153-1161.

Inta D, Alfonso J, von Engelhardt J, Kreuzberg MM, Meyer AH, van Hooft JA, Monyer H. 2008. Neurogenesis and widespread forebrain migration of distinct GABAergic neurons from the postnatal subventricular zone. Proc Natl Acad Sci 105: 20994-20999.

Jabès A, Lavenex PB, Amaral DG, Lavenex P. 2010. Quantitative analysis of postnatal neurogenesis and neuron number in the macaque monkey dentate gyrus. Eur $J$ Neurosci 31: 273-285.

Kempermann G. 2012. New neurons for "survival of the fittest." Nat Rev Neurosci 13: 727-736.

Kempermann G, Kuhn HG, Gage FH. 1997. Genetic influence on neurogenesis in the dentate gyrus of adult mice. Proc Natl Acad Sci 94: 10409-10414.

Kempermann G, Jessberger S, Steiner B, Kronenberg G. 2004. Milestones of neuronal development in the adult hippocampus. Trends Neurosci 27: 447-452.

Klempin F, Kronenberg G, Cheung G, Kettenmann H, Kempermann G. 2011. Properties of doublecortin-(DCX)expressing cells in the piriform cortex compared to the neurogenic dentate gyrus of adult mice. PLoS ONE 6: e25760.

Knoth R, Singec I, Ditter M, Pantazis G, Capetian P, Meyer RP, Horvat V, Volk B, Kempermann G. 2010. Murine features of neurogenesis in the human hippocampus across the lifespan from 0 to 100 years. PLoS ONE 5: e8809.

Korbo L, Amrein I, Lipp HP, Wolfer D, Regeur L, Oster S, Pakkenberg B. 2004. No evidence for loss of hippocampal neurons in non-Alzheimer dementia patients. Acta Neurol Scand 109: 132-139.

Kornack DR, Rakic P. 1999. Continuation of neurogenesis in the hippocampus of the adult macaque monkey. Proc Natl Acad Sci 96: 5768-5773.

Kornack DR, Rakic P. 2001. The generation, migration, and differentiation of olfactory neurons in the adult primate brain. Proc Natl Acad Sci 98: 4752-4757.

Levin I, Kromer B. 2004. The tropospheric ${ }^{14} \mathrm{CO}_{2}$ level in mid latitudes of the northern hemisphere (1959-2003). Radiocarbon 46: 1261-1272.

Levin I, Naegler T, Kromer B, Diehl M, Francey RJ, GomezPelaez AJ, Steele LP, Wagenbach D, Weller R, Worthy DE. 2010. Observations and modelling of the global distribution and long-term trend of atmospheric ${ }^{14} \mathrm{CO}_{2}$. Tellus 62: $26-46$.

Libby WF, Berger R, Mead JF, Alexander GV, Ross JF. 1964. Replacement rates for human tissue from atmospheric radiocarbon. Science 146: 1170-1172.

Luzzati F, De Marchis S, Fasolo A, Peretto P. 2006. Neurogenesis in the caudate nucleus of the adult rabbit. $J \mathrm{Neu}$ rosci 26: 609-621.
Magnusson JP, Goritz C, Tatarishvili J, Dias DO, Smith EM, Lindvall O, Kokaia Z, Frisen J. 2014. A latent neurogenic program in astrocytes regulated by Notch signaling in the mouse. Science 346: 237-241.

Manganas LN, Zhang X, Li Y, Hazel RD, Smith SD, Wagshul ME, Henn F, Benveniste H, Djuric PM, Enikolopov G, et al. 2007. Magnetic resonance spectroscopy identifies neural progenitor cells in the live human brain. Science 318: 980-985.

Maresh A, Rodriguez Gil D, Whitman MC, Greer CA. 2008. Principles of glomerular organization in the human olfactory bulb-Implications for odor processing. PLoS ONE 3: e2640.

McKinnon MC, Yucel K, Nazarov A, MacQueen GM. 2009. A meta-analysis examining clinical predictors of hippocampal volume in patients with major depressive disorder. J Psychiatry Neurosci 34: 41-54.

Ming GL, Song H. 2011. Adult neurogenesis in the mammalian brain: Significant answers and significant questions. Neuron 70: 687-702.

Nakashiba T, Cushman JD, Pelkey KA, Renaudineau S, Buhl DL, McHugh TJ, Rodriguez Barrera V, Chittajallu R, Iwamoto KS, McBain CJ, et al. 2012. Young dentate granule cells mediate pattern separation, whereas old granule cells facilitate pattern completion. Cell 149: 188-201.

Negoias S, Croy I, Gerber J, Puschmann S, Petrowski K, Joraschky P, Hummel T. 2010. Reduced olfactory bulb volume and olfactory sensitivity in patients with acute major depression. Neuroscience 169: 415-421.

Ninkovic J, Mori T, Gotz M. 2007. Distinct modes of neuron addition in adult mouse neurogenesis. J Neurosci 27: 10906-10911.

Nydal R, Lovseth K. 1965. Distribution of radiocarbon from nuclear tests. Nature 206: 1029-1031.

Pagano SF, Impagnatiello F, Girelli M, Cova L, Grioni E, Onofri M, Cavallaro M, Etteri S, Vitello F, Giombini S, et al. 2000. Isolation and characterization of neural stem cells from the adult human olfactory bulb. Stem Cells 18: 295-300.

Palmer TD, Willhoite AR, Gage FH. 2000. Vascular niche for adult hippocampal neurogenesis. J Comp Neurol 425: 479-494.

Pereira AC, Huddleston DE, Brickman AM, Sosunov AA, Hen R, McKhann GM, Sloan R, Gage FH, Brown TR, Small SA. 2007. An in vivo correlate of exercise-induced neurogenesis in the adult dentate gyrus. Proc Natl Acad Sci 104: $5638-5643$.

Rakic P. 1985. Limits of neurogenesis in primates. Science 227: 1054-1056.

Ramm P, Couillard-Despres S, Plotz S, Rivera FJ, Krampert M, Lehner B, Kremer W, Bogdahn U, Kalbitzer HR, Aigner L. 2009. A nuclear magnetic resonance biomarker for neural progenitor cells: Is it all neurogenesis? Stem Cells 27: 420-423.

Rochefort C, Gheusi G, Vincent JD, Lledo PM. 2002. Enriched odor exposure increases the number of newborn neurons in the adult olfactory bulb and improves odor memory. J Neurosci 22: 2679-2689.

Sahay A, Scobie KN, Hill AS, O'Carroll CM, Kheirbek MA, Burghardt NS, Fenton AA, Dranovsky A, Hen R. 2011. 
O. Bergmann et al.

Increasing adult hippocampal neurogenesis is sufficient to improve pattern separation. Nature 472: 466-470.

Sanai N, Tramontin AD, Quinones-Hinojosa A, Barbaro NM, Gupta N, Kunwar S, Lawton MT, McDermott MW, Parsa AT, Manuel-Garcia Verdugo J, et al. 2004. Unique astrocyte ribbon in adult human brain contains neural stem cells but lacks chain migration. Nature 427: 740-744.

Sanai N, Berger MS, Garcia-Verdugo JM, Alvarez-Buylla A. 2007. Comment on "Human neuroblasts migrate to the olfactory bulb via a lateral ventricular extension." Science 318: 393; author reply 393.

Sanai N, Nguyen T, Ihrie RA, Mirzadeh Z, Tsai HH, Wong M, Gupta N, Berger MS, Huang E, Garcia-Verdugo JM, et al. 2011. Corridors of migrating neurons in the human brain and their decline during infancy. Nature 478: 382-386.

Simic G, Kostovic I, Winblad B, Bogdanovic N. 1997. Volume and number of neurons of the human hippocampal formation in normal aging and Alzheimer's disease. $J$ Comp Neurol 379: 482-494.

Spalding K, Bhardwaj RD, Buchholz B, Druid H, Frisén J. 2005a. Retrospective birth dating of cells in humans. Cell 122: $133-143$.

Spalding KL, Buchholz BA, Bergman L-E, Druid H, Frisén J. 2005b. Age written in teeth by nuclear tests. Nature 437: 333-334.

Spalding KL, Arner E, Westermark PO, Bernard S, Buchholz BA, Bergmann O, Blomqvist L, Hoffstedt J, Näslund E, Britton T, et al. 2008. Dynamics of fat cell turnover in humans. Nature 453: 783-787.
Spalding KL, Bergmann O, Alkass K, Bernard S, Salehpour M, Huttner HB, Bostrom E, Westerlund I, Vial C, Buchholz BA, et al. 2013. Dynamics of hippocampal neurogenesis in adult humans. Cell 153: 1219-1227.

Tonchev AB, Yamashima T, Sawamoto K, Okano H. 2005. Enhanced proliferation of progenitor cells in the subventricular zone and limited neuronal production in the striatum and neocortex of adult macaque monkeys after global cerebral ischemia. J Neurosci Res 81: 776-788.

Turetsky BI, Moberg PJ, Yousem DM, Doty RL, Arnold SE, Gur RE. 2000. Reduced olfactory bulb volume in patients with schizophrenia. Am J Psychiatry 157: 828-830.

Wang C, Liu F, Liu Y-Y, Zhao C-H, You Y, Wang L, Zhang J, Wei B, Ma T, Zhang Q, et al. 2011. Identification and characterization of neuroblasts in the subventricular zone and rostral migratory stream of the adult human brain. Cell Res 21: 1534-1550.

West MJ. 1993. Regionally specific loss of neurons in the aging human hippocampus. Neurobiol Aging 14: 287293.

West MJ, Gundersen HJ. 1990. Unbiased stereological estimation of the number of neurons in the human hippocampus. J Comp Neurol 296: 1-22.

Winner B, Cooper-Kuhn CM, Aigner R, Winkler J, Kuhn HG. 2002. Long-term survival and cell death of newly generated neurons in the adult rat olfactory bulb. Eur $J$ Neurosci 16: 1681-1689.

Winner B, Kohl Z, Gage FH. 2011. Neurodegenerative disease and adult neurogenesis. Eur J Neurosci 33: 11391151. 


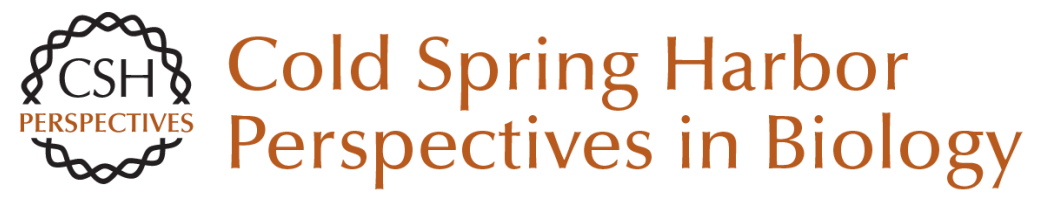

\section{Adult Neurogenesis in Humans}

Olaf Bergmann, Kirsty L. Spalding and Jonas Frisén

Cold Spring Harb Perspect Biol 2015; doi: 10.1101/cshperspect.a018994

Subject Collection Neurogenesis

Adult Neurogenesis and Psychiatric Disorders Eunchai Kang, Zhexing Wen, Hongjun Song, et al.

Neuronal Circuitry Mechanisms Regulating Adult Mammalian Neurogenesis Juan Song, Reid H.J. Olsen, Jiaqi Sun, et al.

Neurogenesis in the Developing and Adult Brain

--Similarities and Key Differences Magdalena Götz, Masato Nakafuku and David Petrik

Genetics and Epigenetics in Adult Neurogenesis Jenny Hsieh and Xinyu Zhao

The Adult Ventricular-Subventricular Zone (V-SVZ) and Olfactory Bulb (OB) Neurogenesis Daniel A. Lim and Arturo Alvarez-Buylla

Diversity of Neural Precursors in the Adult Mammalian Brain Michael A. Bonaguidi, Ryan P. Stadel, Daniel A. Berg, et al.

Detection and Phenotypic Characterization of Adult Neurogenesis H. Georg Kuhn, Amelia J. Eisch, Kirsty Spalding, et al.

Maturation and Functional Integration of New Granule Cells into the Adult Hippocampus Nicolas Toni and Alejandro F. Schinder
Adult Olfactory Bulb Neurogenesis

Pierre-Marie Lledo and Matt Valley

Adult Neurogenesis in Fish Julia Ganz and Michael Brand

In Vitro Models for Neurogenesis Hassan Azari and Brent A. Reynolds

Engineering of Adult Neurogenesis and Gliogenesis

Benedikt Berninger and Sebastian Jessberger

Computational Modeling of Adult Neurogenesis James B. Aimone

Control of Adult Neurogenesis by Short-Range

Morphogenic-Signaling Molecules Youngshik Choe, Samuel J. Pleasure and Helena Mira

Adult Neurogenesis: An Evolutionary Perspective Gerd Kempermann

Epilepsy and Adult Neurogenesis

Sebastian Jessberger and Jack M. Parent

For additional articles in this collection, see http://cshperspectives.cshlp.org/cgi/collection/

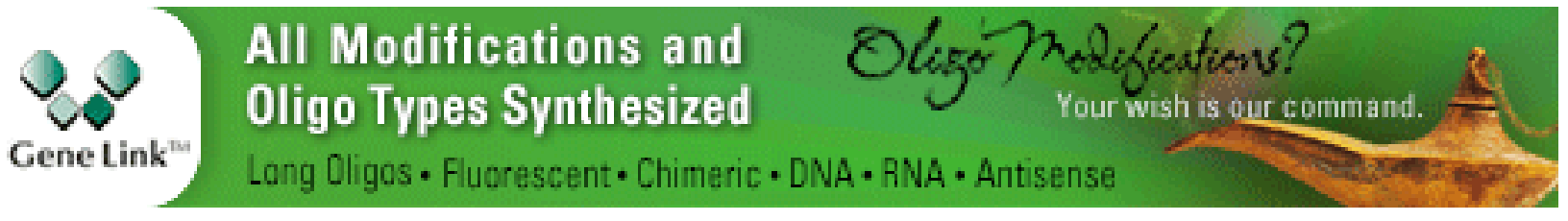

Copyright @ 2015 Cold Spring Harbor Laboratory Press; all rights reserved 